p. $12-14$

4. Ржаницын, А.Р. Теория ползучести [Текст] / А.Р. Ржаницын - М.: Стройиздат. - 1968. - 415 с.

5. Kick, F. Die Prinzipien der mechanischen Technologie und die Festigkeitslehre. Z.Verein.dtsch.Ing. [Text] / F. Kick - 1932. - №10 - p. 26-39

6. Adams, L.H. Philos.Trans.london [Text] / L.H. Adams - 1901. - p. 22-40.

7. Бриджмен, П.В. Исследование больших пластических деформаций и разрыва [Текст] / П.В. Бриджмен - М.:Изд-во иностр.лит-ры, 1955. - 440 с.

8. Бузер, Г.Д. Влияние поровой жидкости на деформационное поведение горных пород при трехосном сжатии [Текст] / Г.Д. Бузер, К.Х., Хиллер, С. Серденгекти // Механика горных пород. - М.:Недра, 1966. - с. 372-406

9. Разрушение. Микроскопические и макроскопические основы механики разрушения [Текст] / Под ред. Г.Либовица. - М.: Мир, 1973. - т.1. - 616 с.

10. Ставрогин, А.Н. Экспериментальная физика и механика горных пород [Текст] / А.Н. Ставрогин, Б.Г. Тарасов - СПб.: Наука, 2001. - 343 с.

11. Линденбратен, Л.Д. Медицинская радиология [Текст] / Л.Д. Линденбратен, Ф.М.Лен. - М.: Медицина, 1986. - 368c.

12. Потапкин, И.Ф. Лабораторный практикум по курсу «Физика горных пород и процессов» [Текст] / И.Ф.Потапкин, А.Г.Томасов, Н.Н.Гавриш и др. Донецк, ДПИ, 1991. - 43 с.

13. Николин, В.И. Особенности проявления горного давления на глубинах 1200м [Текст] / В.И. Николин, Н.В.Игнатович, В.А. Шепеленко // Уголь Украины, 1994. - №5. - c.12-15. $424 \mathrm{c}$.

14. Харин, С.Е. Физическая химия [Текст] / С.Е.Харин - К.:КГУ, 1961. -

15. Миронов, Н.П. Механизм движения жидкости в угольном пласте [Текст] / Н.П.Миронов // Нагнетание воды в угольные пласты для повышения безопасности горных работ. - М.: Недра, 1965. - с. 65-73.

Статья поступила в редакиฺию 09.12.2016 г.

УДК 622.272 .4

DOI: $10.20535 / 2079-5688.2017 .32 .91375$

А.М. Самедов, д.т.н., проф., В.И. Охрименко, магистр (КПИ им. И. Сикорского)

ОЦЕНКА НАПРЯЖЕННО-ДЕФОРМИРОВАННОГО СОСТОЯНИЯ ОСНОВАНИЙ ПОДЗЕМНЫХ СООРУЖЕНИЙ И СПОСОБЫ ИХ УСИЛЕНИЙ

A.M. Samedov, V.I. Okhrimenko (National Technical University of Ukraine "Igor Sikorsky Kyiv Polytechnic Institute") 


\section{EVALUATION OF STRESS-STRAIN STATE FOUNDATIONS UNDERGROUND STRUCTURES AND METHODS OF THEIR GAIN}

Рассмотрено проблемы оценки напряженно-деформированного состояния оснований подземных сооружений и способы их усиления. Разделено напряженное состояние оснований на пространственные и плоские задачи, которые отличаются по компонентам напряжений и методом определения.

В виде примеров подробно проанализировань решение задач относительно $к$ пространственным напряженным состояниям.

Определень нормальные и касательные напряжения для пространственной задачи и дана оценка напряженного состояния оснований, которые могут разрушить вспомогательные сооружения, например, смотровые колодизы под подошвой сооружений, которые находятся на глубине z от подошвы фундаментов сооружений или основания под подошвой фундаментов под колонны.

Ключевые слова: напряженное состояние оснований; пространственные и плоские задачи; фундаменты под колонны, вспомогательные объекты; коллектор; трубопровод; колодец; компоненты напряжений.

Розглянуто проблеми оцінки напружено-деформованого стану основ підземних споруд $i$ способи їх посилення. Розділено напружений стан основ на просторові $i$ плоскі задачі, які відрізняються за компонентами напружень і методом визначення.

У вигляді прикладів докладно проаналізовані рімення задач відносно до просторових напружених станів.

Визначено нормальні і дотичні напруження для просторової задачі $і$ дана оцінка напруженого стану основ, які можуть зруйнувати допоміжні споруди, наприклад, колодязі під фундаментом споруд, які знаходяться на глибині z від поверхні підошви фундаментів cпоруд.

Ключові слова: напружений стан основ; просторові і плоскі задачі; фундаменти під колони, допоміжні об'єкти; колектор; трубопровід; колодязь; компоненти напружень.

The problem of evaluating the stress-strain state of the bases of underground structures and ways of strengthening them. Divided stress state the grounds on spatial and plane problems, which differ in the components and the method of determining stresses.

As an example of a detailed analysis of the tasks relative to the spatial tension.

Determined the normal and shear stresses for the space problem and the evaluation of the stress state of the base which can destroy the supporting facilities, such as wells the reservoir under the sole structures, which are at a depth $z$ from the surface of the base.

Keywords: stress state reasons; spatial and plane problems; foundations under columns, ancillary facilities; collector; pipeline; well; stress components.

Вступление. В некоторых литературных источниках $1 \div 5$ приводятся напряженно-деформированные состояния оснований под подошвой сооружений, однако нет данных оценки этих параметров, которые можно было бы усилить конструкциями вспомогательных объектов от деформаций или разрушений.

Цель работы: дать оценку напряженно-деформированному состоянию оснований подземных сооружений. Рассмотреть способы усиления этих оснований. 
Результаты исследований. Анализ аварийных ситуаций подземных сооружений показывает, что причиной разрушения является превышения напряженного состояния грунтовых оснований от действующих нагрузок по предельной величине прочности грунта. По-этому следует проанализировать возникновение и развитие напряженного состояния грунтовых оснований от воздействия внешних нагрузок, передающихся от сооружений. В общем виде, возникающие напряжения в любой точке над конструкцией вспомогательных объектов оценивается компонентами нормальных $\sigma_{x}, \sigma_{y}, \sigma_{z}$, и касательных $\tau_{x y}$, $\tau_{y x}, \tau_{x z}, \tau_{z x}, \tau_{y z}, \tau_{z y}$ напряжений, направленных по координатным осям $x, y, z$. Если эти 9 компонентов известны, то можна оценить напряженное состояние в этой точке или в конструкциях вспомогательных объектов, таких как колодцы, трубопроводы, коллекторы

Часто грунтовое основание можно считать изотропной средой. В таких случаях пары касательных напряжений становятся равными: $\tau_{x y}=\tau_{y x}$; $\tau_{x z}=\tau_{z x} ; \tau_{y z}=\tau_{z y}$. В таких случаях компонентами напряжений становятся 6 элементов, которые требуется определить.

В инженерной практике все задачи напряженного состояния приводят к двум задачам: пространственной или плоской.

К пространственным задачам относятся напряженное состояние сооружения, размеры которого (ширина и длина) равны или мало отличаются. Например, основание под колонны, дымовые трубы, телевизионные башни, столбы электропередач, основание под односекционные многоэтажные жилые дома, основания под многоярусным подземным гаражом, которые несущими конструкциями является колонны и т.д.

При расчете напряженного состояния оснований, которые относятся к пространственным задачам на изотропном основании (например, под 10-ти ярусном автоматизированным подземным гаражом), в любой точке необходимо определять компоненты напряжений $\sigma_{x}, \sigma_{y}, \sigma_{z}, \tau_{x y}=\tau_{y x} ; \quad \tau_{x z}=\tau_{z x} ; \tau_{y z}=$ $\tau_{z y}$, как показано на рис.1.

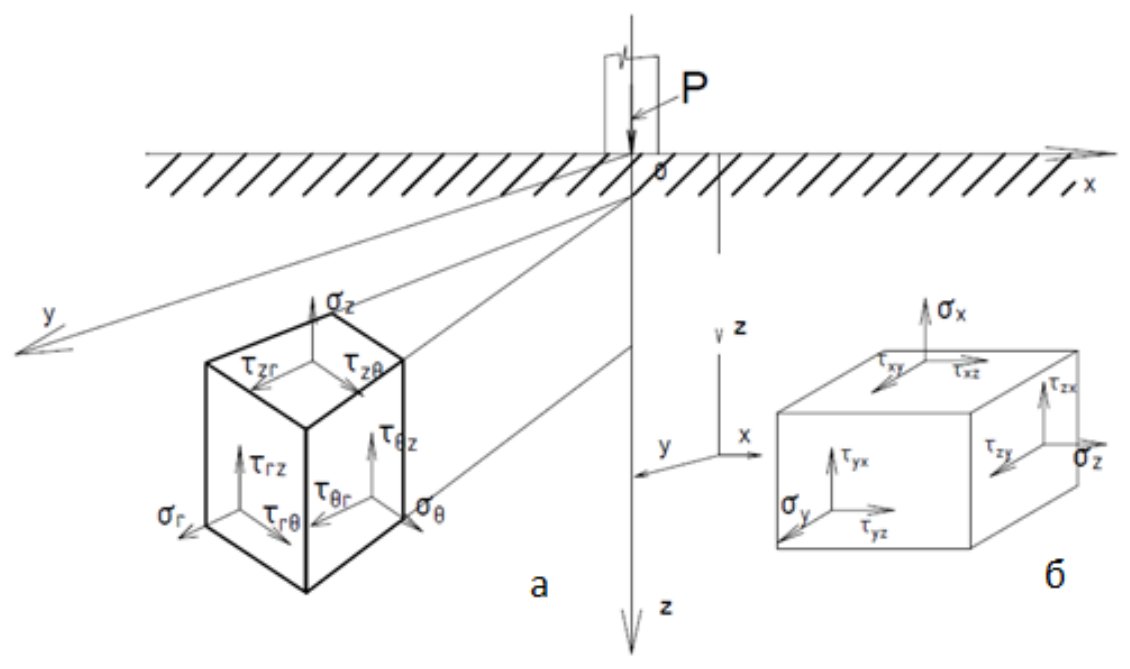

Рис. 1. Пространственная задача:

a - цилиндрическая система координат; $\sigma_{r}, \sigma_{z}, \sigma_{\theta}$ - нормальные компоненты 
напряжений; $\tau_{r z}, \tau_{z r}, \tau_{r \theta}, \tau_{\theta r}, \tau_{z \theta}, \tau_{\theta z}-$ касательные компоненты напряжений;

$\sigma$ - декартовая система координат; $\sigma_{x}, \sigma_{y}, \sigma_{z}$ - нормальные компоненты напряжений; $\tau_{x y}, \tau_{y x}, \tau_{x z}, \tau_{z x}, \tau_{y z}, \tau_{z y}-$ касательные компоненты напряжений

К плоским задачам относится напряженное состояние объекта, у которого в плане один размер (длина) значительно больше, чем другие (ширина). Например основания под коллекторы, трубопроводы, каналы, ленточные фундаменты, тоннели, подпорные стены, автомобильные дороги, пешеходные подземные переходы и т.д.

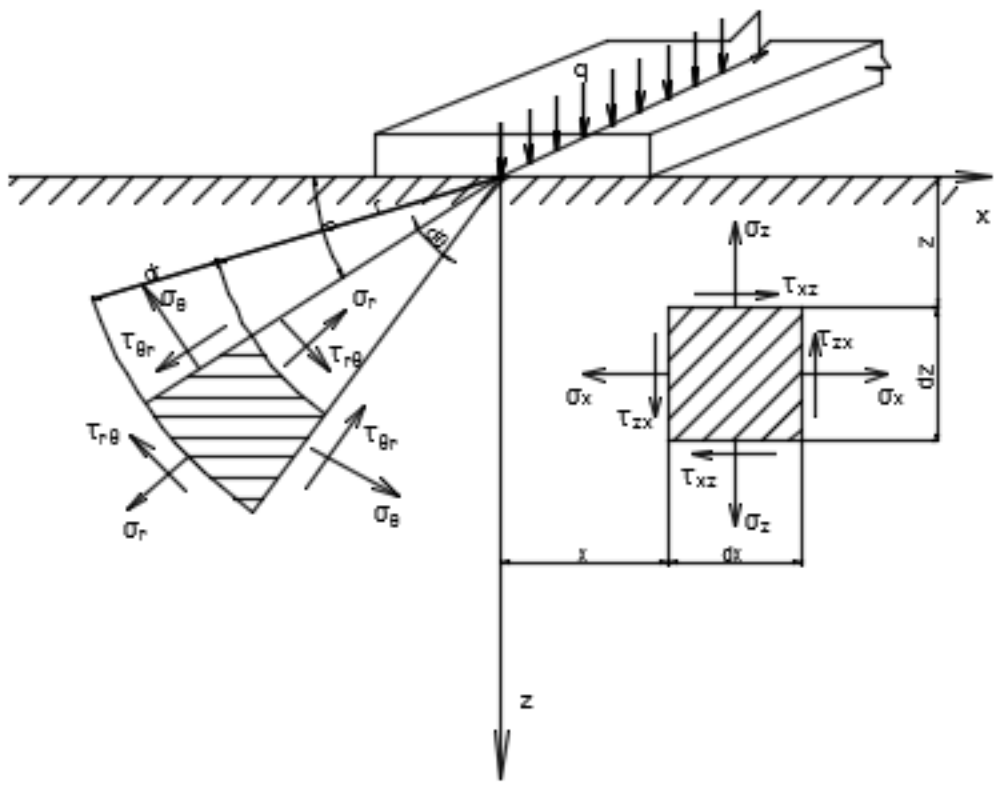

Рис. 2. Плоская задача:

$\mathrm{a}$ - цилиндрическая система координат; $\sigma_{r}, \sigma_{\theta}$ - нормальные компоненты напряжений; $\tau_{r \theta}, \tau_{\theta r}-$ касательные компоненты напряжений;

$\sigma$ - декартовая система координат; $\sigma_{x}, \sigma_{z}-$ нормальные компоненты напряжений; $\tau_{x z}, \tau_{z x},-$ касательные компоненты напряжений

Для решения задач, относящихся к плоским, требуется определить следующие компоненты: $\sigma_{x}, \sigma_{y}, \tau_{x y}, \tau_{y x}$. В случаях изотропных оснований пары касательных напряжений равны, т.е.: $\tau_{x y}=\tau=\tau_{y x}$. Значит, для решения плоских задач необходимо определить 3 компоненты напряжений: $\sigma_{x}, \sigma_{y}, \tau$. рис. 2

Пример. Оценка напряженного состояния по пространственным задачам.

Допустим на поверхности грунтовых оснований от многоярусного автоматизированного подземного гаража, несущими конструкциями которого являются нарощенные по высоте колонны, через фундамент стаканного типа (рис. 3a) передаются условно принятые сосредоточенные нагрузки интенсивностью Р. От воздействия нагрузки Р на грунтовом основании возникают напряженные состояния, которые могут вызвать деформации в конструкции колодца, находящиеся на глубине $\mathrm{Z}$ в произвольной точке $\mathrm{M}$ 
внутри грунтового массива. Требуется определить компоненты напряжений в точке М над колодцем и дать оценку напряженного состояния, влияющего на конструкции колодца и выбрать наиболее прочный материал для конструкции колодца или усилить грунтовый массив в основаниях под сооружением.

Задача относится к пространственным задачам напряженнодеформированного состояния.

Решение. Сначала точку $\mathrm{M}$ соединяем лучами $\mathrm{R}$ с началом действующей нагрузки Р и получаем силу $\sigma_{R}$, которая с вертикальной осью oZ образует угол $\beta$ (рис. 3)
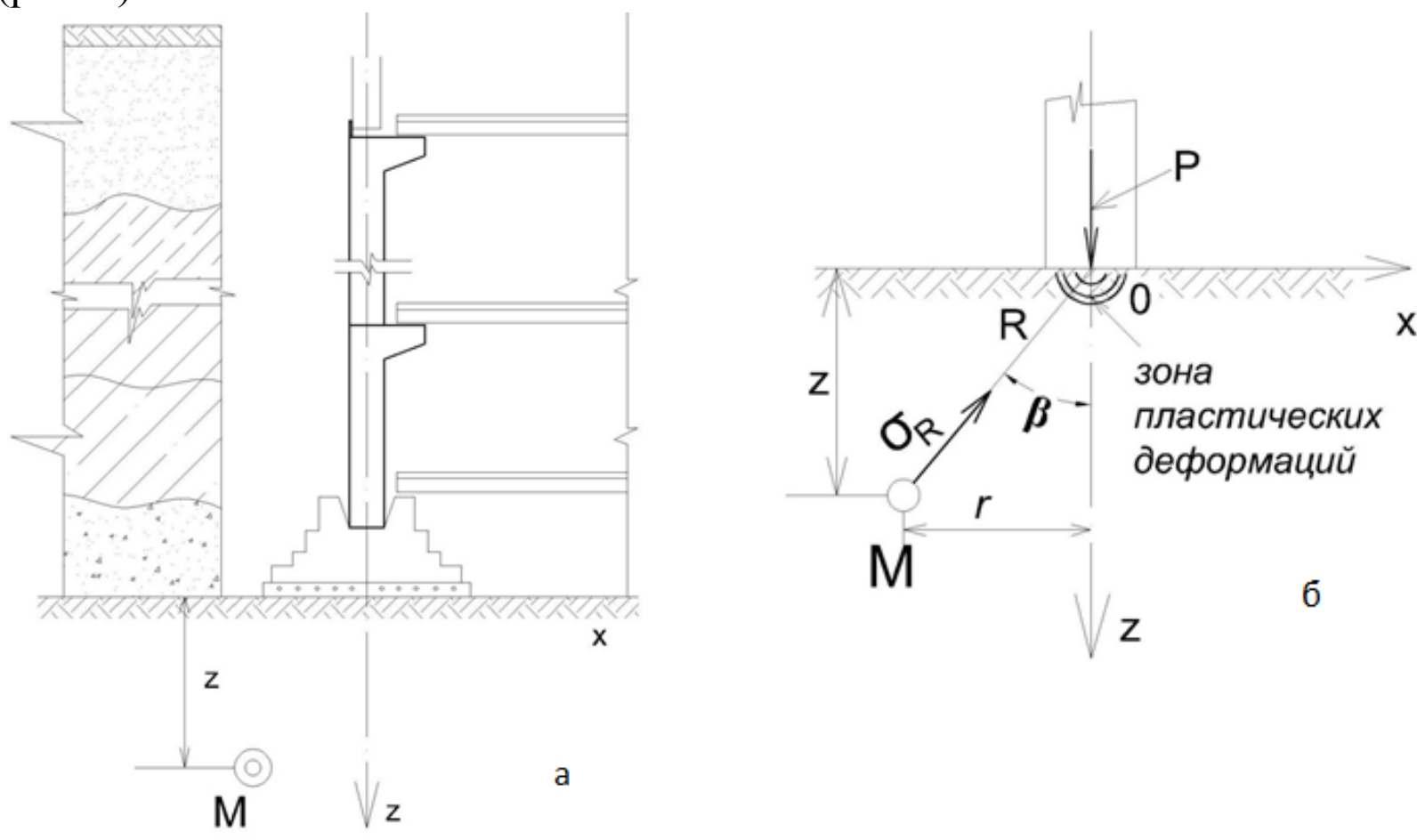

Рис. 3. Пространственное напряженное состояние подземных многоярусных автоматизированных гаражей (a); расчетные схемы (б)

Тогда сила $\sigma_{R}$ будет прямо пропорционально $\cos \beta$ и обратно пропорционально $R^{2}$ с учетом коэффициента $\mathrm{A}$, т.е.:

$$
\sigma_{R}=\mathrm{A} \frac{\cos \beta}{R^{2}}
$$

Согласно условию равновесия $Y_{i}=0$, сумма проекций всех действующий сил в вертикальном направлении (по оси Z) будет равно нулю:

$$
\mathrm{P}={ }_{0}^{\pi / 2} \sigma_{R} \cos \beta d F=0
$$

Здесь $d F$ - поверхность элементарного круглого пояса (если считать, что колонны имеют круглое сечение), определяемого по формуле:

$$
d F=2 \pi(R \sin \beta) R d \beta
$$

Тогда с учетом (3) формула (2) будет:

$$
\mathrm{P}-\mathrm{A} 2 \pi{ }_{0}^{\pi / 2} \cos ^{2} \beta \cdot \sin \beta d \beta=0
$$

Если раскрыть интеграл (4) с граничным условием, то получим:

$$
\mathrm{P}-\frac{2}{3} \pi A=0
$$


Из (5) определяем коэффициент А:

$$
\mathrm{A}=\frac{3}{2} \cdot \frac{P}{\pi}
$$

Значит, радиальный компонент напряжений или силы $\sigma_{R}$ будет иметь вид:

$$
\sigma_{R}=\frac{3}{2} \cdot \frac{P}{\pi R^{2}} \cos \beta
$$

Так как максимальный компонент возникает по оси z, этот компонент напряжений принимает следующий вид:

Если из рис.3,б принимать:

$$
\sigma_{z}=\frac{3 P}{2 \pi} \cdot \frac{z^{3}}{R^{5}}
$$

$$
\mathrm{R}=\overline{x^{2}+y^{2}+z^{2}}=\overline{r^{2}+z^{2}}=z 1+\left(\frac{r}{z}\right)^{2}
$$

Тогда формула максимального компонента $\sigma_{z}$ в точке М будет:

$$
\sigma_{z}=\frac{3 P}{2 \pi} \cdot \frac{1}{1+\left(\frac{r}{z}\right)^{2}{ }^{5}{ }^{2} \cdot z^{2}}
$$

Обозначим $\frac{3}{2 \pi} \cdot \frac{1}{1+\left(\frac{r}{z}\right)^{2}{ }^{5}}=\mathrm{k}$. Тогда (9) получит вид:

$$
\sigma_{z}=k \frac{P}{z^{2}}
$$

Остальные компоненты напряжений будут иметь меньшую величину и их практически не нужно вычислять, однако в чисто теоретическом смысле будет иметь следующий вид:

$$
\begin{gathered}
\sigma_{y}=\frac{3 P}{2 \pi} \cdot \frac{y^{2} z}{R^{5}}+\frac{1-2 \mu}{3} \frac{1}{R(R+z)}-\frac{2 R+Z y^{2}}{R+Z{ }^{2} \cdot R^{3}}-\frac{Z}{R^{3}} \\
\sigma_{x}=\frac{3 P}{2 \pi} \cdot \frac{x^{2} Z}{R^{5}}+\frac{1-2 \mu}{3} \frac{1}{R R+Z}-\frac{2 R+Z x^{2}}{R+Z^{2} \cdot R^{3}}-\frac{Z}{R^{3}} \\
\quad \text { Компоненты касательных напряжений: } \\
\tau_{z y}=\tau_{y z}=\frac{3 P}{2 \pi} \cdot \frac{y z^{2}}{R^{5}} \\
\tau_{x z}=\tau_{z x}=\frac{3 P}{2 \pi} \cdot \frac{x z^{2}}{R^{5}} \\
\tau_{x y}=\tau_{y x}=\frac{3 P}{2 \pi} \cdot \frac{x y z}{R^{5}}-\frac{1-2 \mu}{3} \cdot \frac{(2 R+z) x y}{(R+z)^{2} \cdot R^{3}}
\end{gathered}
$$

Следует отметить, что коэффициент «k» зависит от «r/z» и при значении $\langle\mathrm{r} / \mathrm{z} »=0,00 \quad \mathrm{k}=0,4775 ; \quad$ при $\langle\mathrm{r} / \mathrm{z} »=0,1 \quad \mathrm{k}=0,4657 ; \quad\langle\mathrm{r} / \mathrm{z} »=0,5 \quad \mathrm{k}=0,2733$; $\langle\mathrm{r} / \mathrm{z}\rangle=1,0 \quad \mathrm{k}=0,0844 ;\langle\mathrm{r} / \mathrm{z}\rangle=1,5 \quad \mathrm{k}=0,0251 ; \quad\langle\mathrm{r} / \mathrm{z}\rangle=2,0 \quad \mathrm{k}=0,0085 ;\langle\mathrm{r} / \mathrm{z}\rangle=3,0$ $\mathrm{k}=0,0015$ и при $\langle\mathrm{r} / \mathrm{z} »=5,0 \quad \mathrm{k}=0,0001$ и т.д.

Таким образом максимальный компонент напряжений $\sigma_{z}$ по формуле (10) определяется от величины нагрузки $\mathrm{P}$, от коэффициента «k» и глубины $\mathrm{z}$, a затем значение $\sigma_{z}$ сопоставляется с величиной пределов сопротивления $\mathrm{R}$ материалов колодца, находящиеся в точке М. Если $\sigma_{z}>R_{\text {сооруж, тогда }}$ конструкция колодца будет разрушаться, необходимо выбрать наиболее

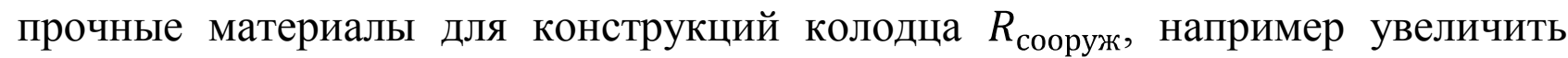
прочность бетона, т.е. принимать высокие классы бетонов или армировать большими количествами арматуры или увеличить толщины конструкций и т.д. 
Если необходимо усилить грунтовые основания, $\sigma_{z}>R_{\text {гр }}$ когда под подошвой подземных сооружений, согласно оценке напряженнодеформированного состояния, тогда принимаются инженерные мероприятия по усилению грунтовых оснований. Существуют различные методы улучшения оснований, такие как: механические (уплотнение трамбованием, виброуплотнение, замена грунтов более прочными, песчаные сваи, шпунтовые ограждения), физические (уплотнение при помощи понижения уровня грунтовых вод, вертикальные дренажи, предварительное обжатие грунтов), химические (цементация, силикатизация, смолизация, термическая обработка и т.д.) или применение свайных фундаментов или конструкции «стена в грунте» и т. д.

\section{Выводы}

На основе из вышеизложенного можно сделать следующие выводы:

1. Напряженное состояние грунтовых оснований подземных сооружений $\sigma_{z}$ в случае превышения предельной велечины прочности или

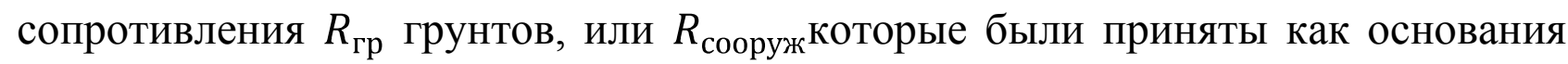
для данного сооружения вызывает деформирование самого сооружения $R_{\text {сооруж }}$ или конструкций вспомогательных объектов находящихся в глубине грунтового массива.

2. Для оценки напряженного состояния вспомогательных объектов подвергающихся воздействию нагрузки от подземных сооружений необходимо сопоставить величины максимальных компонентов напряжений оснований $\sigma_{z}$ возникающих на точке М поверхности конструкций с величиной прочности

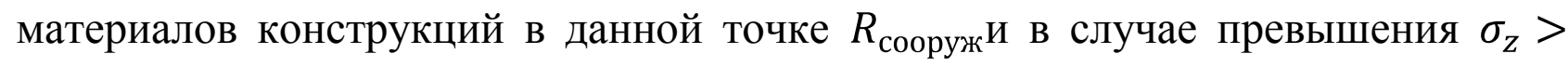
$R_{\text {сооруж }}$ принять меры по усилению конструкции вспомогательного объекта $R_{\text {сооруж }}$ в точке М или усилить грунтовое основание сооружений $R_{\text {гр }}$.

\section{Список использованных источников}

1. Бугров, А.К. О решении смещенной задачи теории упругости и теории пластичности грунтов [Текст] / А.К. Бугров. - Основания, фундаменты и

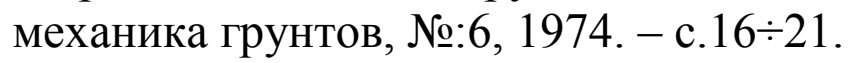

2. Галин, Л. А. Контактные задачи теории упругости и вязкоупругости [Текст] / Л.А. Галин. - М.: Наука, 1980. - с. 303.

3. Гениев, Г.А. Плоская деформация анизотропной идеальнопластической среды [Текст] / Г.А. Гениев. - Строительная механика и расчет сооружений, №:3, 1982. - с. $14 \div 18$.

4. Самедов, А.М. Расчет и проектирование подземных сооружений мелкого заложения (монография) [Текст] / А.М. Самедов. - Киев, НТУУ «КПИ», 2013. - с. 851. 
5. Самедов, А.М. Расчет и проектирование геотехнических инженерных сооружений (монография) [Текст] / А.М. Самедов. - Киев, НТУУ «КПИ», 2013. - с. 806.

Статья поступила в редакциию 29.01.20172.

УДК 622.28.04, 622.81

DOI: $10.20535 / 2079-5688.2017 .32 .90738$

Ю.М. Халимендик, д-р техн. наук, профессор, А.С. Барышников, канд. техн. наук, В.Ю. Халимендик, инженер (ГВУЗ «НГУ»)

\section{ВЗРЫВОБЕЗОПАСНОЕ ИСПОЛЬЗОВАНИЕ ЗАМКОВЫХ СОЕДИНЕНИЙ МЕТАЛЛИЧЕСКОЙ ПОДАТЛИВОЙ КРЕПИ}

Iu. Khalimendik, D. Sc. (Tech.), Professor, A. Baryshnikov, Ph.D. (Tech.), V. Khalimendik, Engineer (State HEI "NMU”)

\section{EXPLOSION-PROOF USAGE OF THE STEEL YIELDING SUPPORT JOINT CLAMPS}

У статті розглядається проблема безпечної експлуатаиї податливого кріплення зі спеипрофілю СВП.

Розглянуті деформачії замкових з'єднань у шахтних умовах. Наведені результати стендових випробувань замкових з'єднань. Показано, що при роботі замкового з'єднання чергується взаємне зчеплення й ковзання елементів податливого вузла з перекосом скоб. Різкий перехід зі зчеплення в ковзання супроводжується стрибком скоб з іскроутворенням. Температура й час життя іскор достатні для запалення метаноповітряної суміші.

Для виключення іскроутворення запропонована вдосконалена конструкиія замка податливості, щзо усуває його перекіс.

Ключові слова: замкове з'єднання; вузол податливості; спецпрофіль СВП; метаноповітряна суміш; запалення; іскра; вибухобезпечність.

В статье рассматривается проблема безопасной эксплуатаџии податливой крепи из спецпрофиля СВП.

Рассмотрены деформащии замковых соединений в шахтных условиях. Приведены результаты стендовых испытаний замковых соединений. Показано, что при работе замкового соединения чередуется взаимное сиепление и скольжение элементов податливого узла с перекосом скоб. Резкий переход из сиепления в скольжение сопровождается скачком скоб с искрообразованием. Температура и время жизни искр достаточны для воспламенения метановоздушной смеси.

Для исключения искрообразования предложена усовершенствованная конструкияи замка податливости, устраняющая его перекос.

Ключевые слова: замковое соединение; узел податливости; спецпрофиль СВП; метановоздушная смесь; воспламенение; искра; взрывобезопасность.

The problem of the safe operation of the steel yielding support made of V-shape profile 